\title{
A força dos Atos Insubordinados: a performatividade entre o direito e a política
}

\author{
The force of the Unruly Acts: performativity between law and politics
}

\author{
Deonardo Monteiro Crespo de Almeida \\ Doutor em Direito pela Faculdade de Direito do Recife/UFPE \\ Mestre em Direito pela Faculdade de Direito do Recife/UFPE \\ Bacharel em Direito pelas Faculdades Integradas Barros Melo \\ Bacharel em Filosofia pela Universidade Federal de Pernambuco/UFPE. \\ leonardoalmeida326@gmail.com
}

\begin{abstract}
Resumo
O presente artigo tem como objetivo analisar algumas implicações político-jurídicas dos atos e enunciados que não se subordinam propriamente às normas e condições institucionalizadas que, a rigor, permitiriam que viessem a produzir os seus efeitos. Tomando como principais referências teóricas os trabalhos de Jacques Derrida, Judith Butler e Drucilla Cornell, este artigo argumenta que a falta de conformidade dos atos performativos, em contextos institucionalizados, pode levar a implicações políticas consideráveis nos espaços jurídicos. Essas implicações abrangem tanto a criação de novos direitos, como mudanças significativas no âmbito das relações sociais, trazendo à tona formas de desigualdade e relações de opressão que fragilizam ainda mais a situação de grupos minoritários. Ao subverterem certas convenções estabelecidas, os performativos trazem consigo a promessa de uma nova sociedade, uma em que aquelas relações de opressão não seriam mais admitidas.
\end{abstract}

Palavras-chave: Performatividade. Desconstrução. Derrida. Novos direitos.

\section{Abstract}

This present article intends to develop a few sociolegal implications of performative acts and statements that do not conform themselves to the established norms and conditions that otherwise would allow them to produce the effects intended by the speaker. The article takes as its main theoretical references the works of Jacques Derrida, Judith Butler and Drucilla Cornell in order to argue that the non-conformity of the said acts within institutional contexts could lead to significant political implications in the legal space, such as the creation of new rights and major changes in social relations. Those implications in different ways expose inequalities and forms of oppression of minority groups as important problems that must be dealt with. By subverting established conventions, performatives acts bring with themselves images of a future society, one in which those relations of oppression could no longer be accepted.

Keywords: Performativity. Deconstruction. Derrida. New rights.

\section{Introdução}

Um aspecto importante das práticas políticas e jurídicas reside na maneira como os atos realizados nestes domínios produzem efeitos decorrentes da validação por regras e preceitos constitutivos do espaço no qual aqueles atos são realizados. Para além dos 
conteúdos a serem transmitidos, essa dimensão performativa traz à tona a capacidade de moldar, intervir e transformar os contextos nos quais os atos são realizados. Uma sentença judicial ou uma intimação, para além de representar um dado estado de coisas, também atua impondo certas orientações de ação. As orientações, por sua vez, somente podem ser impostas através da conformação do ato de sentenciar, inclusive da autoridade que sentencia, às normas jurídicas constitutivas do espaço no qual a sentença é produzida, a saber, o poder judiciário.

Cada ato jurídico, ao produzir os efeitos esperados, altera, acrescenta ou subtrai algo ao panorama no qual se encontra inserido. A sentença judicial que condena alguém a uma determinada pena introduz uma relação que, antes de sua enunciação, não existia, a saber, a obrigação de cumprimento da pena pelo réu, agora condenado. Este ato transforma o réu em condenado, o cidadão livre em alguém que deverá cumprir uma pena por certo período, alterando de maneira significativa relações previamente fixadas.

Certas decisões judiciais, especialmente aquelas tomadas nas cortes superiores, produzem consequências que extrapolam as determinações jurídicas da própria decisão. Alguns casos como Roe v. Wade ou Brown v. Board of Education pela Suprema Corte NorteAmericana, ou julgamento da Ação Direta de Inconstitucionalidade (ADI) 3.510 ou o julgamento das ADI 4.277/ADPF 132 pelo Supremo Tribunal Federal, por exemplo, trazem ressonâncias políticas explícitas, enquanto essa mesma dimensão política, em outros atos, é mais implícita (DWORKIN, 2011, p. 377). Essa oscilação entre os segmentos do social é, conforme o entendimento sustentado nesse artigo, característico dos efeitos performativos.

O objetivo central dessa pesquisa reside em desenvolver algumas implicações referentes à indeterminação dos atos performativos que se encontram na interseção entre o direito e a política. Considerando as diversas maneiras pelas quais os atos podem alterar e subverter os contextos nos quais se encontram inseridos, quais podem ser as consequências que interligam a política e o direito? Será mesmo que os efeitos dos atos jurídicos se limitam tão somente ao contexto imediato das suas enunciações? A hipótese de pesquisa é a seguinte: a produção dos efeitos dos atos performativos não reside apenas na conformação entre ele e as condições de um dado campo uma vez que o ato pode ser apropriado e deslocado em circunstâncias futuras das mais diversas.

O que a hipótese pretende averiguar é se a indeterminação desses efeitos a partir de uma concepção de futuro aberta e contingente, logo insuscetível de ser demarcado através das disposições normativas presentes no campo, não poderia vir a compor uma ponte entre o político e o jurídico. Certamente as implicações normativas de uma decisão judicial já se 242 
fazem presentes logo após ela ser tomada, mas o sentido dessa decisão pode, meses ou décadas depois, assumir uma forte conotação política, servindo inclusive de referência para as estratégias e mobilizações de grupos desfavorecidos.

$\mathrm{Na}$ primeira parte serão tecidas algumas considerações gerais sobre a noção de performatividade e a sua relação com os chamados contextos institucionais, ou seja, espaços marcados por procedimentos e regras que estabelecem as condições de aceitabilidade e validade dos atos e dos proferimentos. $\mathrm{O}$ cerne desta seção reside em confrontar a estabilidade dos contextos institucionais e, deste modo, demarcar a possibilidade de que os efeitos dos atos extrapolam os limites estabelecidos nesses contextos.

A segunda parte trata de situar, de maneira mais específica, a performatividade no âmbito jurídico tendo como fio condutor as condições sociais, extralinguísticas, que respaldam a produção dos seus efeitos, assim como estabelece as condições de sua validação. A ideia central nesta seção reside no impacto político dos atos que, a rigor, são primeiramente caracterizados como jurídicos. Essa oscilação do jurídico ao político decorre, por vezes, do itinerário percorrido pelo ato em meios às diversas circunstâncias nas quais ele é apropriado após a sua manifestação inicial.

A última seção recorre ao conceito de domínio imaginário da autora Drucilla Cornell com o propósito de explorar o potencial político dessa insubordinação do performativo. A maneira pela qual os performativos podem não satisfazer plenamente as expectativas vigentes, ou mesmo rejeitá-las, descreve bem o hiato entre as condições concretizadas e o imaginário utópico de mudanças que ainda estão por vir, a exemplo da aquisição de novos direitos e o fim de relações opressivas. Para isso se recorre também, de maneira sucinta, a certas considerações feministas.

O domínio imaginário faz com que o jurídico e o político se tornem indissociáveis, especialmente ao repensar valores que são fundamentais para as práticas desses dois campos, a exemplo da igualdade. É esse domínio imaginário que, de algum modo, faz-se presente nos atos de militantes políticos, de protestos e passeatas que confrontam o status quo, que, ao denunciaram relações sociais opressivas, articulam um novo imaginário social no qual essas relações não sejam mais toleradas. Pretende-se conectar o presente e o futuro dos performativos numa interseção entre o jurídico e o político.

Em termos metodológicos, a pesquisa desenvolve uma abordagem sincrética e multifacetada da performatividade, em vários pontos distanciando-se de sua exposição original, na obra de J. L. Austin, How to do Things with Words, e de John R. Searle, optando 
por se deter majoritariamente na leitura realizada por Jacques Derrida e por autores por ele influenciados, como Samuel Weber e Judith Butler. Na última seção, para fins de desenvolver analiticamente a relação entre o político e o jurídico no tocante aos performativos, uma leitura seletiva das obras de Drucilla Cornell e novamente Butler, especialmente no tocante a maneira como os performativos permitem trazer à tona as condições de sua enunciação e mesmo confrontá-las, foi crucial para o desenvolvimento do fio condutor desta pesquisa.

\section{Performatividade e as ambivalências dos contextos institucionais}

O ponto inicial referente à performatividade reside na forma como atos linguísticos realizam algo dentro de um certo cenário: realizar implica transformar ou enquadrar de algum modo o cenário no qual se atua (MILLER, 2007, p. 221; AUSTIN, 1962, p. 5). Recorrendo a duas situações bastante corriqueira nesses estudos, quando um padre celebra um casamento ou alguém batiza um navio, nas duas cenas existe a inserção de estados e configurações que previamente não existiam, a saber, a relação matrimonial e a atribuição de um nome próprio a um navio que até então lhe faltava (SEARLE, 1989, p. 536 ; AUSTIN, 1962, p. 8 e ss). As alterações pelas quais sofrem cada um dos cenários reflete, por sua vez, a produção dos efeitos inscrita nos atos mencionados.

Uma vez que não se confunde com os enunciados estritamente constativos, restritos à descrição de uma situação em particular, a forma pela qual eles serão avaliados será distinta dos critérios associados ao primeiro tipo de enunciado (DERRIDA, 1988, p. 13 e ss). James Loxley destaca um ponto crucial no tocante à dinâmica dos performativos, a saber, a maneira como as fronteiras entre o enunciado e o evento são dissolvidas. Loxley observa:

\footnotetext{
De início, o critério da validação ou justificação pelo qual os proferimentos constativos são devedores, a saber, o da verdade enquanto correspondência de um enunciado com os fatos de uma situação particular, não se pode dizer que se aplicam inteiramente deste modo aos performativos, uma vez que os proferimentos já são parte, e talvez a parte mais importante, dos fatos: não existe separação, logo nenhuma relação para que nós avaliemos, entre o proferimento e a situação. $O$ proferimento não pretende descrever uma situação, um evento ou uma ação: ele é o evento ou a ação (LOXLEY, 2007, p. 8).
}

Se os enunciados performativos constituem o próprio evento, disso não se segue, por sua vez, que a sua existência se encontre dissociada de qualquer critério de validação. Pelo contrário, a produção dos efeitos, que permite o surgimento de uma ação ou evento, depende também de uma concordância prévia com uma série de condições presente nesses cenários, não necessariamente explícita que vão permitir a produção - ou não - desses efeitos 
(SEARLE, 1989, p. 539 ; AUSTIN, 1962, p. 8). Algumas dessas condições se refletem na competência dos entes para realizarem esses atos e a forma com a qual esses atos são levados adiante, caso a formalidade de algum modo atue como requisito para a produção desses efeitos.

Agora, supondo que o padre responsável pela realização da cerimônia seja, por sua vez, um impostor sem as qualidades eclesiásticas que lhe permitiriam celebrar um casamento reconhecido pela igreja, quais seriam os efeitos e o valor de uma situação que, ao final, mostrou-se falsa e carente de um elemento crucial para que fosse configurada a sua validade? E se o juiz que celebra um casamento é, na verdade, um excelente ator disfarçado, quais também seriam os efeitos da celebração? É disso que, em tese, trata-se a ideia de força referente à produção dos efeitos dos atos, ou seja, a relação que possuem com as condições de validade estabelecidas nos contextos que envolvem esses atos (DERRIDA, 1988, p. 14).

Esse tipo de relação é constitutivo dos espaços marcados pela determinação de regras e procedimentos voltados à validação dos atos, como o âmbito jurídico. Não é suficiente que uma petição ou uma sentença possua uma fundamentação juridicamente adequada, já que ela também precisa ser elaborada - ou validada - por alguém que preencha o tipo de competência necessária, como advogados e juízes, além de que também necessita atentar para uma certa forma pré-estabelecida, responsável por ditar quais elementos são essenciais para a peça. Um contexto institucional existe a partir do momento em que se demarca uma série de condições normativas ao passo que exclui outras que não se mostram compatíveis com os seus pressupostos, o que inclui a demarcação dos lugares autorizados para a enunciação e a realização de certos atos. Samuel Weber observa:

\footnotetext{
A noção de instituição presente no texto que se segue é uma em que a organização instituída e o processo de instituição se juntam na relação ambivalente de cada estrutura determinada que exclui algo, e, ainda assim, aquilo que é excluído permite que a estrutura se mantenha à parte (WEBER, 2001, p. xv)
}

Ora, essa relação ambivalente entre a maneira como um contexto organiza a si mesmo e aquilo que ele exclui, não daria margens para uma interpretação circular, onde um termo, para a sua compreensão, sempre vai remeter a um outro e assim sucessivamente? Um contexto $a$, por sua vez, já não se encontraria inserido em um contexto $b$ que lhe é mais amplo, e assim em diante? Como seria possível determinar plenamente os efeitos de um ato performativo se o seu sentido oscila e se diferencia com base nos contextos em que se encontra inserido? 
O processo de institucionalização, em tese, resolveria esse problema ao remeter o contexto a um conjunto de práticas coletivas e habituais características de uma comunidade específica e que, por isso mesmo, podem ser tomadas como pressupostos da interpretação e verificação dos enunciados. Longe de ser subjetiva, a avaliação dos enunciados seria uma prática coletivamente construída através das interações e práticas comunitárias. Nisso residiria também uma noção ampla de institucionalização, ou seja, da sedimentação de certas regras e limites que, a princípio, garantiriam a estabilidade e a continuidade dessas práticas.

Nesse processo de institucionalização, porém, as próprias referências institucionalizadas - e que compõem o processo interpretativo já que são tomadas como ponto de partida - também passam pela interpretação que, a princípio, tendem a orientar. Instaura-se uma relação circular na qual instituição e interpretação se entrelaçam, em certo sentido similar à maneira pela qual os atos performativos produzem - ou não - efeitos em meio aos contextos nos quais se inserem. Recorrendo ao pragmatismo de Charles Sanders Peirce, Samuel Weber ressalta:

\footnotetext{
A formação e a modificação do que Peirce descreveu como "hábitos" depende das tradições coletivas e das instituições pelas quais eles são transmitidos e reproduzidos. Mas se a instituição das interpretações específicas demanda a interpretação de instituições específicas, Peirce terá refinado a nossa sensibilidade para a instabilidade intrínseca e violenta tanto da instituição quanto da interpretação, e também o embate inevitável que elas proporcionam (WEBER, 2001, p. 17).
}

Em uma direção distinta, mas que certamente guarda associações com o que fora estabelecido por Peirce, Derrida ressalta a impossibilidade de saturação dos contextos e a força de ruptura dos signos que, embora dissociados da intenção original dos seus autores e mesmo das circunstâncias originárias de sua enunciação, permanecem compreensíveis. Essa insubordinação aos limites do contexto permite que o signo se desloque de contexto em contexto sem que deixe de comunicar ou exprimir algo, mesmo que distante e distinto das intenções originárias do falante (DERRIDA, 1988, p. 9).

Impedir a força de ruptura presente no signo recorrendo à ideia de um contexto plenamente determinado é algo que por sua vez remete diretamente à estrutura fechada do pensamento metafísico, ancorado em um fundamento último e, por isso mesmo, auto evidente, a exemplo de Deus, o nome próprio que por si só se explicaria. Ora, uma vez que esse fundamento é questionado através do próprio deslocamento das relações diferenciais que permeiam a estrutura, a determinação da estrutura, seja ela o pensamento metafísico ou o contexto do qual se falou, é abalada, levando a uma instabilidade em sua constituição. Weber observa: 
O que ocorre dentro do clausura da Metafísica já fora nomeado uma vez, aquilo que jamais deixou de seguir adiante, é o ser-nomeado, o Ser do nome, o que vem, vem e vai, tornar-se sem nunca chegar a uma destinação própria, o telos do Ser. E este não chegar, sempre vindo, em contrapartida, faz com que o "interior" da Metafísica, ou qualquer outra coisa que lhe é associada, seja virado ao avesso. Sem o nome próprio, sem o ser-próprio do nome, nenhuma distinção entre o dentro e o fora, o antes e o depois, frente e trás, pode ser estabelecida de uma vez por todas (WEBER, 2001, p. 96).

Essa intricada passagem assinala a instabilidade subjacente às diversas demarcações operadas pelos contextos institucionais. O conceito tal como defendido neste trabalho remete a um conjunto de regras e enunciados que determinam quem pode falar, como se pode falar e quais atos podem ser considerados válidos. São esses conjuntos de regras que também estabelecem as condições pelas quais os atos performativos são validados ou não. O que se pode extrair da passagem de Weber sobre este ponto é que nenhum contexto é evidente por si só, nem termos ou enunciados são evidentes por si só, sendo tão somente vinculados ao seu sentido literal, como Derrida bem considerou (DERRIDA, 1988, p. 2)

Da interpretação textual aos atos performativos, por mais evidente que pareça se mostrar o contexto do proferimento e/ou do ato, as suas fronteiras desses contextos são instáveis o bastante para que sejam continuamente redefinidas e deslocadas. Nenhum contexto consegue se fechar completamente em torno de si mesmo a partir de fundamento último. Se os contextos institucionais, a princípio, servem para conter os efeitos dos atos performativos, demarcando o seu sentido e as suas consequências, observa-se, nessa passagem, que as próprias condições e regras que caracterizam um dado contexto, por sua vez, necessitam ser interpretadas e manipuladas. É nessa circularidade oscilante que os performativos se desdobram: ao mesmo tempo em que guardam relação com condições prévias para que possam produzir os seus efeitos, os performativos permitem também colocar em questão e mesmo confrontar essas mesmas condições (DERRIDA, 1988, p. 22).

\section{$2 \mathrm{O}$ poder dos performativos e as condições sociopolíticas do campo jurídico}

Um dos grandes problemas da teorização da linguagem de Saussure e J. L. Austin, por mais diversas que sejam as suas perspectivas e pressupostos teóricos, reside em isolar e pretender compreender o poder das manifestações da linguagem através da própria linguagem, o que foi bem observado por Derrida ao apontar que os performativos em Austin são concebidos tão somente como atos de comunicação (DERRIDA, 1988, p. 13 e ss). Por mais que a performatividade assim compreendida dependa dos contextos nos quais os 
proferimentos ocorrem e realizam algo, parece ter sido de pouco interesse do autor investigar as condições sociais que integrariam esses contextos.

Uma análise que desconsidera a autoridade e a competência do orador, necessárias para a produção dos efeitos dos atos performativos, tende a permanecer atrelada tão somente aos elementos sintático-semânticos dos enunciados. Mesmo que se reconheça que, no que concerne à força ilocucionária do falante, a retórica do orador, a sua posição social, o reconhecimento que ele possui diante do seu auditório, sejam elementos determinantes, ainda assim a abordagem permaneceria restrita a uma concepção formal e interna da linguagem. Pierre Bourdieu tece o seguinte comentário a respeito do vínculo entre a produção de efeitos e o campo institucional responsável por autorizar o falante:

De fato, o uso da linguagem, tanto a forma quanto a substância do discurso, depende da posição social do falante, que governa o discurso oficial, ortodoxo e legítimo. É o acesso aos instrumentos legítimos de expressão, e portanto de participação na autoridade da instituição, que faz toda a diferença - irredutível ao discurso como tal - entre a falsidade dos fingidores, que disfarçam um proferimento performativo como um enunciado descritivo ou constativo, e a impostura autorizada daqueles que fazem o mesmo, mas possuindo a autorização e a autoridade da instituição (BOURDIEU, 1991a, p. 109).

Bourdieu chama atenção para algo de importância significativa, analisando o vínculo entre performatividade e espaços institucionais: a maneira como a autoridade do falante não apenas se encontra diretamente associada à efetividade do discurso, como é construída em meio ao campo no qual ele se insere. A delimitação operada pelo campo fornece as condições de efetividade dos discursos oficiais, muito embora essas condições estejam sujeitas às transformações através das práticas constitutivas desse domínio.

Estabelece-se deste modo uma associação entre as estruturas sintático-semânticas dos enunciados, elas mesmas socialmente construídas, e as condições sociais que vão autorizar o discurso em questão. Estas condições, porém, na perspectiva de Derrida, não são suficientemente fortes para impedir a violência, as transformações e a maneira como os atos podem produzir efeitos e transformações para além dos contextos originários em que foram enunciados (BARTON, 2003, p. 231; MILLER, 2007, p. 229; DERRIDA, 2002, p. 251).

Toda ação é sempre um encontro de séries causais independentes. Seja, de um lado, as disposições linguísticas que são socialmente construídas, atribuindo certa propensão para que o falante se expresse e determine o seu entorno, além de uma certa capacidade para que se possa falar, capacidade esta que contempla tanto as regras gramaticais que permitem um discurso aceitável no entorno, como também a capacidade social que estabelece o uso 248

Prisma Jur., São Paulo, v. 18, n. 2, p. 241-260, jul./dez. 2019 
adequado, pelo falante, nas situações nas quais ele se encontra a partir de um campo particular. Por outro lado, Bourdieu observa, existem estruturas sociais subjacentes à constituição de cada um dos campos que estabelece formas de restrições e reprovações diante daquilo que é enunciado (BOURDIEU, 1991b, p. 37).

No campo jurídico, teorias do direito e construções dogmáticas desempenham o papel de formatação e limitação dos discursos disponíveis nos espaços institucionais. Explicitamente ou não, essas teorias estabelecem o que é aceitável, válido e relevante em certos domínios do campo (BOURDIEU, 1989, p. 211). Neste ponto, a circularidade da interpretação a qual o processo de institucionalização pretende conter se reflete nas diversas formas de interpretação e implementação das teorias do direito e das construções dogmáticas: o campo jurídico é, antes de mais nada, um campo marcado por controvérsias e disputas pela determinação do que conta como verdadeiro e válido (BOURDIEU, 1989, p. 217).

Ao apontar a instabilidade dos contextos que circunscrevem os proferimentos, Derrida descreve uma dupla relação na qual a repetição dos enunciados é também a condição de possibilidade pela qual a repetição pode ser rompida para que uma nova série de acontecimentos possa ocorrer (BARTON, 2003, p. 229; DERRIDA, 1988, p. 7). O caso de Rosa Parks é ilustrativo para abordar as implicações políticas do performativo, especialmente no tocante às rupturas que podem provocar nos contextos institucionais no qual se inserem.

$\mathrm{Na}$ época em que a doutrina jurídica dos separados, mais iguais (separate but equals) estava em pleno vigor nos Estados Unidos, o acesso aos transportes públicos era organizado através de critérios raciais, incluindo a determinação dos lugares para a permanência de cada etnia. A doutrina já havia sido validada pela Suprema Corte Americana no caso Plessy v. Ferguson de 1896: o fundamento da decisão fora o de que a segregação racial da décima quarta emenda voltada à proteção da igualdade se os estabelecimentos destinados à cada etnia estivessem em condições equivalentes.

Uma decisão como essa não somente apresenta uma possibilidade interpretativa referente a um elemento da Constituição, como também assinala um entendimento institucional sobre a segregação racial. Embora em sua natureza jurídica, a decisão reconfigura os debates e as mobilizações sociais referentes a uma temática política que vai se tornar ainda mais crucial e urgente algumas décadas adiante.

Neste panorama social, na hipótese em que o transporte público estivesse lotado, os afrodescendentes necessariamente precisariam ceder o seu lugar a um transeunte branco. Encontrando-se nessa situação em particular, Rosa Parks se recusou a ceder o seu lugar, 
levando a um conflito direto com as autoridades dispostas por fazer valer as determinações normativas constitutivas daquele espaço. Contestar essas determinações implica, primeiramente, reconhecê-las, toma-las como ponto de partida, para que possam ser confrontadas.

Em uma análise centrada no contexto imediato no qual o ato fora manifestado, as consequências da recusa de Parks levaram à sua detenção, mas uma vez que se considere as diversas apropriações do ato discordante, apropriações que em muito ultrapassaram os limites geográficos do ato em questão, então o potencial político da performatividade pode e a indeterminação dos contextos nos quais se insere pode ser devidamente vislumbrado (BIRLA, 2011, p. 498). Foi a recusa de Parks, em uma situação pontual, que contribuiu para o fortalecimento de grupos como os Panteras Negras (Black Panthers) e o movimento em prol dos direitos civis.

Os limites institucionais que demarcam o contexto no qual a decisão fora tomada terminaram sendo assimilados a um panorama político mais amplo e multifacetado, também abalado de maneira significativa pela decisão. As implicações e os significados de Roe $v$. Wade foram amplas o suficientes para afetar muitos dos espaços, discussões e termos da sociedade estadunidense até então estabelecidos, a exemplo dos direitos das mulheres, da mencionada privacidade, mas também de um imaginário social no qual a igualdade de todos perante a lei passa a contemplar a desigualdade de gênero até então naturalizada e pouco tematizada no âmbito jurídico.

Considerar a performatividade deste modo envolve explorar uma abertura futura na qual as demarcações estabelecidas pelas práticas institucionalizadas não podem ser apreendidas. Dito de outro modo, a conformação - ou a não-conformação, a sua insubordinação - de um ato ou enunciado às condições de validação inscritas em um contexto institucional podem levar à produção de efeitos neste espaço, mas estes, por sua vez, trazem consigo um potencial de repetição e de inserção em novas situações nas quais os limites institucionais previamente estabelecidos não dispunham de controle.

Ora, os atos performativos podem simplesmente subverter as demarcações estabelecidas através da imprevisibilidade dos seus efeitos e mesmo na caracterização deles. Como classificar o ato de Parks? Por certo, trata-se de um ato político, mas seria também jurídico? A princípio ele não fora praticado em um espaço jurídico institucionalizado. $\mathrm{O}$ ato, no entanto, teve implicações diretas, na vereda aberta pela decisão unanime em Brown v. 
Board of Education, para as discussões e mobilizações referentes aos direitos civis que ainda hoje encontram a sua ressonância.

Essa instabilidade que acompanha a organização do campo jurídico permite abri-lo, mesmo que por vezes de maneira restrita, a outros imaginários sociais nos quais as relações presentes possam ser definitivamente reconfiguradas, a exemplo da passagem entre Plessy $v$. Ferguson até Brown v. Board of Education. Se a passagem em muito se deveu às transformações sociais que perpassaram os contextos nos quais as decisões foram tomadas, é importante vislumbrar nessas mudanças a maneira como os diversos atos, inclusive decisões judiciais, modificaram também as ideias mais gerais referentes acerca da sociedade estadunidense (JACKSON, 1994, p. 169). Em síntese, a politização do direito decorre do comprometimento incalculável da justiça que precisa se fazer presente no âmbito calculável e instrumental das normas jurídicas (GLENDINNING, 2016, p. 190).

\section{Confrontando o presente em busca de novos futuros: performatividade e o domínio imaginário}

Um dos pontos centrais deste artigo consiste em insistir na dimensão política dos performativos especificamente no que concerne à sua abertura futura, ou seja, a maneira pela qual um ato ou enunciado pode ser indefinidamente apropriado em novos contextos dissociados daqueles nos quais foram originalmente submetidos. Uma consequência política importante é que, se por um lado os contextos institucionais buscam apreender e fixar os efeitos dos atos através das suas demarcações, a própria significação da língua, o que abrange os atos performativos, depende, como observara Derrida, da possibilidade de sua repetição (DERRIDA, 1988, p. 15).

O futuro calculado e organizado através das disposições normativas constitutivas de cada campo é, por sua vez, justaposto a um futuro contingente e indeterminado, e que por essa razão se subtrai ao cálculo. No âmbito jurídico, as normas jurídicas expressam uma forma de normatividade fundada sob uma concepção de futuro em termos de cálculo (DERRIDA, 2002, p. 244; GLENDINNING, 2016, p. 189).

A ideia de domínio imaginário é desenvolvida por Drucilla Cornell quando indaga pela dimensão utópica que revestiria o feminismo e que também acaba sendo um dos pontos nos quais ele vem a ser atacado. Diferentemente do futuro planejado que perfaz as reformas e os planejamentos que norteiam a política institucional, a utopia revelaria uma perigosa falta 
de tanto não somente com a realidade, mas também com as expectativas em termos de transformações.

Entretanto, como bem observara Michael Walzer, muito embora as conquistas trazidas pelos movimentos sociais, a exemplo dos movimentos trabalhistas e sindicais norteamericanos da década de trinta ou dos movimentos que lutaram pelos direitos civis na década de sessenta, tenham sido bem menores do que as suas metas, ainda assim proporcionaram transformações na distribuição de receitas e do reconhecimento de direitos outrora ignorados (WALZER, 2012, p. 28). Essas razões, em parte, esclarecem o porquê do domínio imaginário proposto pelas feministas ser veemente combatido por vários segmentos do social, especialmente aqueles heterossexuais: a ambição utópica desses ideais permite e orienta a mobilização de inúmeras pessoas em prol de mudanças persistentes e significativas no espaço social.

A própria maneira como a rejeição se coloca é, sob o aspecto da performatividade, bastante significativa para ilustrar uma confluência entre as concepções subjetivas de cada um em torno do papel e dos lugares que podem ser ocupados por mulheres e uma compreensão jurídica mais ampla e formal que considera a igualdade de todos perante a lei, sem distinção. Uma vez que essas duas concepções se entrelaçam, as concepções individuais acabam por se sobrepor e determinar o horizonte mais amplo do direito no qual todos estão submetidos. Provocações como "feminazi" e outros proferimentos expressam, dentre outros afetos, inseguranças e insatisfações em meio a mudanças que potencialmente redefinem, especialmente na seara jurídica, as relações entre os gêneros.

Explorar o potencial da igualdade enquanto valor que circunscreve as demandas feministas passa por considerar uma descontinuidade entre o domínio, mais individual e substancial, do 'bom' do domínio, mais amplo e formal, do 'direito'. Essa descontinuidade simultaneamente engloba as convicções individuais de cada um ao mesmo tempo em que as distingue das determinações normativas mais gerais e que se impõem a todos. Cornell observa:

A tese da descontinuidade demanda que nós separamos as nossas próprias concepções individuais acerca do 'bem' daquilo que nós podemos impor a todos como uma questão de direitos, consideradas a igualdade que possuímos enquanto pessoas. Vislumbrar o domínio imaginário como forma de endossar um tipo de vida sexual ou de associação íntima é se equivocar quanto as bases filosóficas pelas quais ele é defendido. A separação entre direito e bom é crucial para o reconhecimento de nossa igualdade jurídica porque as nossas convicções mais profundas acerca do que seria apropriado sexualmente para nós pode nos fazer levar a acreditar que a nossa forma de pensar é a única maneira (CORNELL, 1998, p. 176). 
A performatividade do discurso de ódio não se limita apenas a ofender ou desmerecer a posição que lhe é contrária, mas estabelece, ainda que de maneira sutil, ao menos dois pontos de grande importância: primeiro, tende a mobilizar crenças, valores e orientações normativas em pressupostos que, ao menos em tese, servem de amparo para a sua rejeição; segundo, ao procederem deste modo, abrem espaço, mesmo que involuntariamente, para que se possa questionar as bases e/ou o direcionamento que o discurso pretende estabelecer.

O termo "feminazi”, por exemplo, traduz bem essa dupla orientação: por um lado, expressa a preocupação em se proteger certas formas de vida nas quais a figura masculina assume preponderância e centraliza a sua influência; por outro lado, a ansiedade abre espaço para que se esclareça e se conteste todo um regime normativo que, transpassando vários domínios institucionais, negou às mulheres prerrogativas jurídicas que lhe são suas, que há muito lhe foram concedidas, mas que carecem de uma presença mais incisiva em suas formas de vida. São direitos que carecem de um reconhecimento enraizado nas práticas cotidianas daqueles domínios e, em vários casos, da sociedade em geral.

A descontinuidade se revela quando a forma com que um casal de lésbicas concebe a família e a criação dos seus filhos não necessariamente precisa ser aquela de um casal heterossexual, antes as duas concepções podem coexistir em suas respectivas esferas sem que as normas jurídicas imponham uma dessas opções. Essas normas podem fornecer referências de comportamento que levem a uma compreensão da igualdade comprometida em assegurar a coexistência de compreensões diversas sobre as relações sociais, e é disso que se refere o domínio imaginário mencionado por Cornell. Mas de que maneira essa igualdade estaria associada a uma subjetividade inscrita na interseção entre o jurídico e o político?

De início a própria demanda por direitos serve para reinscrever aquele que demanda em um sistema estabelecido de categorias e identidades que lhe circunscrevem a ação: demandas jurídicas existem a partir de condições políticas e regimes disciplinares que permitem e validam a sua interposição (SPADE, 2011, p. 447). Uma situação ilustrativa reside na demanda das mulheres, em muitas democracias ocidentais, pela ampliação e a observância dos seus direitos sociais, especificamente dos care rights. No ato da demanda por direitos se faz presente um processo de interpelação que enquadra a identidade feminina em diversas formas de regulação e controle, sejam eles jurídicos, políticos, econômicos, dentre outros (ELEVELD, 2015, p. 86). O reconhecimento de um direito passa igualmente pelo reconhecimento da subjetividade jurídica daquele que o demanda. 
Dentre as várias nuances que podem ser identificadas em torno da subjetividade, uma delas é bem apontada por Cornell: a aspiração contínua, projeção futura que confronta e interroga as aspirações atuais. A pessoa não é um dado efetivo da existência, e sim uma possibilidade constante, tal como os performativos (CORNELL, 1995, p. 5). A liberdade de se tornar pessoa depende de um conjunto de condições prévias que vão lhe permitir o exercício de sua individualidade, principalmente no tocante às suas opções existenciais. Como observa Cornell, a identidade da pessoa é um processo contínuo de interrogação: é projeto, percurso, ao invés de ponto no qual se chega, cessando com isso os questionamentos e conflitos (CORNELL, 1995, p. 5). Sem essas condições prévias que permitam a individuação, a ideia mesma de pessoa pode se esvaziar em uma concepção de igualdade sufocante e estagnada (JACKSON, 1994, p. 169).

Os direitos trazem consigo o potencial - e se trata sempre de um potencial - de transformação simbólica e material das condições existenciais de indivíduos e pessoas. Demandar um direito pode ser concebido também como um ato político no qual uma certa configuração social é confrontada em sua falta, carência ou insatisfação, expondo a precariedade da forma de vida de um seguimento da população (ELEVELD, 2015, p. 94; BUTLER, 2009, p. ii). A própria ausência de materialidade daquilo que se demanda, a exemplo de direitos de seguridade social que fortaleçam a situação da mulher no mercado de trabalho, suscita debates em torno de qual caminho as transformações coletivas que afetam essas questões deve ser tomado (ELEVELD, 2015, p. 94; BUTLER, 2009, p. ii). Sendo um espaço complexo e amplo, o direito oferece um panorama atravessado metas e inclinações concorrentes, para não dizer opostas, materializados em táticas e estratégias que incidem na organização do social (SPADE, 2011, p. 456).

O poder da performatividade simultaneamente contempla a existência de um domínio como esse ao passo em que não desconsidera as diversas ações e proferimentos que lhe são contrárias. Se os efeitos dos performativos não se exaurem, nem se limitam, aos contextos nos quais foram originalmente enunciados, então a utopia da qual fala Cornell pode ser concebida não apenas como um referencial normativo implícito nos discursos que assinalam transformações sociais, como também abrangem os atos e enunciados que se colocam contra essas mudanças, abrindo espaço tanto para que seus fundamentos e pressupostos sejam problematizados, como para que as suas consequências, principalmente em termos de uma imagem geral do social, possam ser trazidas à tona. Por trás de um termo como "feminazi”, que imagem de sociedade se encontram e onde se pretende chegar? 
Se cada ato sempre pode se constituir em uma referência para um ato posterior, então ele traz consigo as condições de sua própria subversão. No mencionado incidente de Rosa Parks, portanto, não foi a recusa em ceder o seu lugar que foi subvertida, mas a imediata reação em que lhe reprovar a conduta e a sua subsequente detenção, que também trazem consigo um significado claro quanto ao imaginário social que as autoridades queriam reforçar.

O incômodo trazido pelo feminismo e por movimentos que problematizam as relações de gênero, que se materializa em termos depreciativos como "feminazi" ou "ideologia de gênero", paradoxalmente apontada para a sua significação e força nos espaços mais diversos espaços do social, dentre eles o jurídico. Traduzem um anseio pela limitação de direitos e a consequente restrição de prerrogativas juridicamente conquistadas. Em síntese, mesmo que não seja esse o objetivo dos discursos injuriosos, eles acabam por colocar em evidência as diversas inclinações e normas sociais invisíveis no momento mesmo em que depreciam e ofendem.

A associação do performativo com os discursos de ódio, especialmente em termos de subversão das pretensões explicitamente estabelecidas por esses discursos foi minunciosamente explorada por Judith Butler na sua obra Excitable Speech. Dentre as diversas passagens e ideias que a autora analiticamente desenvolve no tocante à possibilidade de uma reversão dos atos performativos injuriosos, pode-se destacar a seguinte:

\begin{abstract}
A possibilidade política de retrabalhar a força do ato de fala contra a força da injúria consiste reside em uma falsa apropriação da força do ato dos seus contextos anteriores. A linguagem que se opõe às injúrias do discurso, no entanto, necessita repetir essas agressões sem precisamente reativá-las. Tal estratégia afirma que o discurso de ódio não destrói a agência necessitária para uma resposta crítica (BUTLER, 1997, p. 40).
\end{abstract}

Butler destaca um potencial político que implicitamente guarda conexões significativas com as considerações de Derrida discutidas ao longo deste trabalho, principalmente quando ela situa a contraposição entre os atos de fala e a instabilidade dos contextos que envolve a enunciação dos atos. É em meio a essa contraposição em que a abertura a um futuro contingente e incontrolável traduz também a possibilidade mencionada pela filósofa de se retrabalhar os atos de fala de modo a resguardar as condições para uma resistência crítica, acentuando também possibilidades de transformação implícitas na própria circunstância (BIRLA, 2011, p. 500).

O que também está em questão neste ponto é o despertar de uma certa autorreflexão presente nos segmentos minoritários acerca da maneira pelo qual tanto os seus enunciados quanto os seus atos não são dotados de significação política. A resistência surge como uma 
forma de politização de aspectos do social outrora não confrontados: o ato de resistência, para além do seu conteúdo locucionário, assinala também a emergência de um sujeito político em uma circunstância que lhe é estranha. Sobre essa questão em particular, Butler observa:

[...] a performatividade ocorre quando aqueles que não são contados mostra a reflexividade e passam a contar a si próprios, não apenas enumerando quem são, mas "aparecendo" de alguma forma, exercendo um "direito" (extralegal, certamente) à sua existência. Eles se tornam relevantes. Nós podemos compreender isso de maneira mais ampla como uma forma de produção do sujeito político na medida em que o sujeito é um efeito político deste exercício mesmo (BUTLER; ATHANASIOU, 2013, p. 101).

$\mathrm{O}$ apelo a um direito que supostamente se deveria ter, mas que ainda não integra a estrutura do ordenamento jurídico positivo, pode, a rigor, ser desconsiderado como um enunciado carente de fundamentação jurídica, mas a significação política do gesto é nítida: demandar aquilo que ainda não se tem é uma forma de problematizar uma lacuna e confrontar a estrutura institucional que lhes deixa de lado. Exercer um direito é também expressar características e possibilidades próprias à subjetividade jurídica: demandar um direito é um ato que politicamente assiná-la a ausência de condições em um dado contexto institucional para que uma certa prerrogativa possa ser de consideração jurídica.

Diferentemente da formulação inicial deste artigo, onde a produção dos efeitos estava associada ao preenchimento das condições dos contextos institucionais, a maneira como Butler explora a reapropriação dos atos de fala converge com precisão para a noção de domínio imaginário empregada por Cornell: o que está em questão não é a adesão ou preenchimento dos enunciados e formas de agir nos contextos institucionais, e sim a maneira como esses contextos podem ser enfrentados. Ofensas e injúrias abrem espaço para uma problematização dos pressupostos implícitos que permitem a existência e a reprodução dessas ofensas, o que, por sua vez, pode levar a uma visualização de transformações nessas circunstâncias. Por mais paradoxal que seja, o não-reconhecimento do direito ou a negação de sua existência abrem espaço para uma problematização das circunstâncias mais amplas, inclusive institucionais, que validam esse quadro jurídico.

Se Brown v. Board of Education redefiniu o direcionamento do debate racial, no espaço mais restrito e ritualizado das cortes judiciais, assim o fez em função das diversas ações que problematizaram as restrições raciais impostas - e amparadas - por leituras da Constituição norte-americana. Ao invés de se conformarem às determinações normativas vigentes, fossem elas sociais ou jurídicas, os atos de protesto acolheram as injúrias, as 
humilhações e o tratamento desigual de modo a trazer à tona um domínio imaginário que, por definição, apresentava uma configuração social diversa daquela que até então se fazia atual.

\section{Conclusão}

A pretensão do artigo consistiu em mostrar a importância de uma análise da performatividade no âmbito institucional do direito. Para tanto, tomou como ponto de partida a produção dos efeitos dos atos performativos, nos contextos institucionais, em termos de uma adequação que eles possuem com as normas assentadas. $\mathrm{O}$ passo seguinte residiu em apontar como a produção desses efeitos não se restringe às demarcações propostas pelos contextos institucionais. Para além das hipóteses de sobreposição dos contextos institucionais, o que dificulta a determinação de quais são as regras e os critérios válidos que devem ser preenchidos para que o ato de fala venha a produzir os efeitos que lhe são esperados, o artigo tratou de abordar a maneira como os atos trazem consigo uma dimensão temporal que impede que os seus efeitos se restrinjam aos limites dos contextos.

Se uma das características dos contextos institucionais se revela nas normas que estabelecem as condições pelas quais um ato pode ser validado, o que se tem é também uma concepção de futuro calculável nos termos dos conteúdos normativos vigentes. Uma vez considerado o sentido dessa dimensão temporal, o artigo tratou de apontar certas implicações políticas dos atos de fala que podem convergir para a transformação dos contextos institucionais que os circundam: em detrimento da imagem de futuro apreendida e determinada pelas normas dos contextos institucionais, os performativos trazem consigo um futuro absolutamente contingente e elusivo. Atos que, a princípio, são rechaçados nesses contextos ou mesmos considerados de pouca significação, adiante podem acabar sendo o ponto de partida para novas mobilizações que contribuem para uma intervenção. Nestes casos, a produção dos efeitos se deve à inadequação, ao invés da conformação, às condições dos contextos.

Para fins ilustrativos, a pesquisa recorreu à noção de domínio imaginário proposta por Drucilla Cornell e à análise dos atos de fala injuriosos feita por Judith Butler para desenvolver analiticamente as implicações dessa inadequação e a maneira como os contextos institucionais podem ser transformados. O domínio imaginário abrange os anseios, as expectativas e os desejos por novas formas de socialização que ainda não encontram plena aceitação - ou concretização - no atual panorama da sociedade, mas que por isso mesmo constitui um horizonte simbólico que vai nortear as ações e as estratégias daqueles que propõem mudanças. 
É próprio do domínio imaginário apresentar uma falta de conexão com a realidade institucional vigente por conta de sua dimensão utópica.

Os atos de fala injuriosos, por sua vez, revelam uma faceta de grande significação para o estudo dos performativos nos contextos institucionais: a possibilidade de não apenas serem citados adiante, como nesse processo permite também a subversão do seu sentido originário. Aquele que almeja ofender e desmerecer um grupo de pessoas traz à tona, ainda que implicitamente, os pressupostos e convicções dos quais parte e que, por sua vez, abrem-se para um exame crítico. Em síntese, a enunciação dos atos injuriosos permite, deste modo, a exposição de pressupostos, por vezes implícitos e/ou dissimulados nas práticas institucionalizadas, abrindo espaço para o questionamento não só do ato em si mesmo, mas do panorama mais amplo no qual ele se insere e extrai a sua força.

De decisões judiciais de grande abrangência, a exemplo dos casos Roe v. Wade e Brown v. Board of Education, até a recusa específica, mas politicamente motivada, de Rosa Parks em não se submeter às determinações políticas de seu tempo, as implicações dos performativos extrapolam as circunstâncias mais imediatas de sua enunciação e mesmo as expectativas quanto à extensão e à intensidade dos seus efeitos. Nos exemplos mencionados, cada ato traz consigo a promessa de uma sociedade mais igualitária no qual os diferentes segmentos sociais possam ser tratados com igual consideração e respeito.

Investigar os performativos no contexto institucional do direito implica em considerar não apenas a maneira pela qual certos atores são investidos da autoridade para fazer valer os seus enunciados, como também as possibilidades que existem para que esses enunciados sejam deslocados e repensados à luz de outros contextos, inclusive mais amplos. Se as decisões judiciais podem ser resgatadas em julgados subsequentes, por si só apreciados em condições muito distintas daquelas originárias, pode-se dizer que os atos performativos trazem consigo uma abertura que não pode ser fechada, nem controlada, pelas determinações institucionais mais imediatas.

A conclusão central desta pesquisa é a seguinte: a análise da força dos performativos precisa levar em consideração as diversas maneiras pelas quais os seus efeitos são produzidos e de que maneira esses efeitos alteram os diversos contextos nos quais eles, os atos, acabam circulando. Se os atos jurídicos, como diversos outros atos inscritos em contextos institucionais, são dotados de performatividade, é importante destacar também a maneira como eles podem vir a subverter as condições nas quais eles surgem e são reconhecidos. A possibilidade de subversão abre espaço para a formulação e o reconhecimento de demandas 
jurídicas que outrora ofuscadas pelas forças políticas estabelecidas. As maneiras pelas quais os performativos intervêm em seus respectivos contextos institucionais não podem ser apreendidas de antemão pelas regras que imediatamente norteiam os contextos nos quais eles se inserem.

\section{Referências}

AUSTIN, J. L. How to do things with Words. London: Clarendon Press, 1962.

BARTON, J. C. Iterability and the Order-Word Plateau: 'A Politics of the Performative' in Derrida and Deleuze/Guattari. Critical Horizons, v. 4, n. 2, pp. 227-264, 2003.

BIRLA, R. Performativity Between Logos and Nomos: Law, Temporality and The "NonEconomic Analysis of Power". Columbia Journal of Gender and Law, v. 21, n. 2, pp. 492$515,2011$.

BOURDIEU, P. A força do direito: elementos para uma sociologia do campo jurídico. In: BOURDIEU, P. (org). O poder simbólico. Rio de Janeiro: Bertrand, 1989, pp. 209-254.

BOURDIEU, P. Authorized Language: the social conditions for the effectiveness of ritual discourse. In: BOURDIEU, P; THOMPSON, J. B (org.). Language and Symbolic Power. Cambridge: Polity Press, 1991a, pp. 107-116.

BOURDIEU, P. The Economy of linguistic exchanges: introduction. In: BOURDIEU, P.; THOMPSON, J. B (org.). Language and Symbolic Power. Cambridge: Polity Press, 1991b, pp. 37-42.

BUTLER, J. Excitable speech: a politics of the performative. New York: Routledge, 1997. BUTLER, J. Performativity, Precarity and Sexual Politics. Revista de Antropología Iberoamericana, v. 4, n. 3, Dec/2009, pp. i-xiii.

BUTLER, J; ATHANASIOU, A. Dispossession: the performative in the political. Cambridge: Polity Press, 2013.

CORNELL, D. At the heart of freedom: feminism, sex, and equality. Princeton: Princeton University Press, 1998.

CORNELL, D. The imaginary domain: abortion, pornography and sexual harassment. London: Routledge, 1995.

DERRIDA, J. Force of law: the mystical foundation of authority. In: DERRIDA, J.;

ANIDJAR, G. (org). Acts of Religion. New York: Routledge, 2002, pp. 228-298.

DERRIDA, J. Signature Event Context. In: DERRIDA, J; GRAFF, G. (org). Limited Inc. Northwestern University Press, 1988. pp. 1-24.

DWORKIN, R. Justice for hedgehogs. Cambridge: Harvard University Press, 2011. 
ELEVELD, A. Claiming care rights as a performative act. Law and Critique, v. 26, pp. 83$100,2015$.

GLENDINNING, S. Derrida and the philosophy of law and justice. Law and Critique, v. 27 , pp. 187-203, 2016.

JACKSON, E. Imagining The future: Drucilla Cornell's Transformations and Catharine MacKinnon’s Only Words. Law and Critique, v. 5, n. 2, pp. 165-174, 1994.

LOXLEY, J. Performativity. London: Routledge, 2007.

MILLER, J. H. Performativity as Performance / Performativity as Speech Act: Derrida's Special Theory of Performativity. South Atlantic Quarterly, v. 106, n. 2, pp. 219-235, 2007.

SEARLE, J. R. How performatives work. Linguistics and Philosophy, v. 12, pp. 535-558, 1989.

SPADE, D. Law as tactics. Columbia Journal of Gender and Law. v. 21, n. 2., pp. 442-473, 2011.

WALZER, M. Should we reclaim political utopianism? European Journal of Political Theory, v. 12, n. 1, pp. 24-30, 2012.

WEBER, S. Institution and interpretation. Stanford: Stanford University Press, 2001.

Recebido em 07 abr. 2019 / Aprovado em 12 dez. 2019

Para referenciar este texto:

ALMEIDA, Leonardo Monteiro Crespo de. A força dos Atos Insubordinados: a performatividade entre o direito e a política. Prisma Jurídico, São Paulo, v. 18, n. 2, p. 241260, jul./dez. 2019. https://doi.org/10.5585/PrismaJ.v18n2.13463. 